OPEN ACCESS

Edited by:

Haitao Shi,

Hainan University, China

Reviewed by:

Kyoungwhan Back,

Chonnam National University, South

Korea

Yang-Dong Guo,

China Agricultural University, China

*Correspondence:

Rüdiger Hardeland rharde/@gwdg.de

Specialty section: This article was submitted to Plant Cell Biology,

a section of the journal

Frontiers in Plant Science

Received: 04 December 2015 Accepted: 04 February 2016 Published: 19 February 2016

Citation: Hardeland R (2016) Melatonin in Plants - Diversity of Levels and Multiplicity of Functions.

Front. Plant Sci. 7:198. doi: 10.3389/fpls.2016.00198

\section{Melatonin in Plants - Diversity of Levels and Multiplicity of Functions}

\author{
Rüdiger Hardeland* \\ Metabolism Research, Johann-Friedrich-Blumenbach Institute for Zoology and Anthropology, University of Göttingen, \\ Göttingen, Germany
}

Melatonin has been detected in numerous plant species. A particularly surprising finding concerns the highly divergent levels of melatonin that vary between species, organs and environmental conditions, from a few pg/g to over $20 \mu \mathrm{g} / \mathrm{g}$, reportedly up to $200 \mu \mathrm{g} / \mathrm{g}$. Highest values have been determined in oily seeds and in plant organs exposed to high UV radiation. The divergency of melatonin concentrations is discussed under various functional aspects and focused on several open questions. This comprises differences in precursor availability, catabolism, the relative contribution of isoenzymes of the melatonin biosynthetic pathway, and differences in rate limitation by either serotonin $\mathrm{N}$-acetyltransferase or $\mathrm{N}$-acetylserotonin $\mathrm{O}$-methyltransferase. Other differences are related to the remarkable pleiotropy of melatonin, which exhibits properties as a growth regulator and morphogenetic factor, actually debated in terms of auxin-like effects, and as a signaling molecule that modulates pathways of ethylene, abscisic, jasmonic and salicylic acids and is involved in stress tolerance, pathogen defense and delay of senescence. In the context of high light/UV intensities, elevated melatonin levels exceed those required for signaling via stress-related phytohormones and may comprise direct antioxidant and photoprotectant properties, perhaps with a contribution of its oxidatively formed metabolites, such as $N^{1}$-acetyl- $N^{2}$-formyl-5-methoxykynuramine and its secondary products. High melatonin levels in seeds may also serve antioxidative protection and have been shown to promote seed viability and germination capacity.

Keywords: antioxidant, auxin-like, circadian, photoprotection, seeds, senescence, stress

\section{INTRODUCTION}

Melatonin, once discovered in vertebrates as a hormone of the pineal gland, is now known to be formed in bacteria and numerous taxa of eukaryotes including various algae of different phylogenetic position and plants (Hardeland and Fuhrberg, 1996; Hardeland et al., 2007b; Tan et al., 2014b; Hardeland, 2015), whereas the presence of melatonin in archaea is still uncertain (Tan et al., 2014b). In addition to melatonin, recently discovered isomers of this molecule have been shown to also exist in some plants (Tan et al., 2014b). However, their full spectrum of abundance and their functional roles are not yet sufficiently known.

The fact that melatonin is an ancient molecule present in numerous phylogenetically distant organisms raises questions concerning the identity or similarity of functions. Some of them might be suspected to reflect fundamental cell biological requirements already existent before or at the basis of eukaryotic evolution. On the other hand, the billions of years since then may have been sufficient to allow the acquisition of secondary, additional functions that may entirely differ 
between taxa. This can be assumed to be also the case within the viridiplantae and even the embryophyta. In fact, strong evidence exists for such a functional diversity.

After the first discovery of melatonin in a phototrophic organism, the dinoflagellate Lingulodinium polyedrum (syn. Gonyaulax polyedra; Poeggeler et al., 1989, 1991; Balzer and Hardeland, 1991) and, thereafter, in macroalgae (Fuhrberg et al., 1996) and plants (Dubbels et al., 1995; Hattori et al., 1995), investigators tried to identify classic functions of this compound known from vertebrates, such as transmission of the signal 'darkness' and regulation of seasonality and circadian rhythmicity. The idea of possibly having found an agent mediating information on the length of scotophase, as in mammalian seasonal breeders, led to hopes concerning a role in plant photoperiodism. However, the first precondition, namely, existence of a high-amplitude circadian melatonin rhythm with a nocturnal maximum, was not generally fulfilled. Such a rhythm was demonstrated in L. polyedrum (Poeggeler et al., 1991; Balzer et al., 1993) and in a few plants, in particular, a short-day ecotype of Chenopodium rubrum (Kolár et al., 1997), but not generally in macroalgae and plants. In C. rubrum, no flower induction by melatonin was observed (Kolár and Macháčková, 2005). Instead, flowering was partially suppressed when given late at night. A similar effect was obtained with a putative pharmacological agonist, CGP 52608, considered as a ligand of an assumed mammalian nuclear melatonin receptor (Kolár et al., 1999). However, this transcription factor is actually no longer regarded as a melatonin-binding protein (Slominski et al., 2014). Moreover, neither melatonin nor its bioactive metabolite 5-methoxytryptamine induced flowering in several lemnaceans and in the crassulacean Kalanchoë tubiflora, another short-day plant (Hardeland and Poeggeler, 2003; Hardeland et al., 2007b). Therefore, a role in photoperiodism of plants seems unlikely, although this cannot be ruled out for other, phylogenetically distant phototrophic organisms, such as dinoflagellates (Balzer and Hardeland, 1991; Hardeland et al., 1995).

In recent years, transcriptomic, proteomic and metabolomic studies conducted in different plants such as Arabidopsis thaliana (Weeda et al., 2014; Qian et al., 2015), Malus hupehensis (Wang et al., 2014a) and Cynodon dactylon (Shi et al., 2015b,f) have revealed a plethora of melatonin-induced changes in the expression of genes at mRNA and protein levels as well as in metabolite concentrations. A remarkable diversity of actions was observed in different fields of function, which indicates a pleiotropic, orchestrating role of melatonin reminiscent of that known from animals (cf. Hardeland et al., 2011).

Within plants, another strong hint for a diversity of functions can be deduced from the extreme species- and organ-specific differences in melatonin concentration, which range from almost or totally undetectable to levels of above 20 or $30 \mu \mathrm{g} / \mathrm{g}$, as summarized elsewhere (Hardeland et al., 2007b; Arnao, 2014). Recently, melatonin contents of up to $200 \mu \mathrm{g} / \mathrm{g}$ were reported to exist in kernels of several Iranian Pistacia vera cultivars (Oladi et al., 2014). It seems highly unlikely that such extremely high amounts serve the same function as low concentrations of a few $\mathrm{pg} / \mathrm{g}$, which would be in a range of vertebrate levels and may be compatible with the role of a signaling molecule. In dry seeds, under conditions of strongly reduced metabolism and gene expression and in the absence of circadian rhythmicity, melatonin might have a specific function differing from those in tissues with active metabolism (Balzer and Hardeland, 1996).

Even if the particular situation of seeds is left apart, other considerable differences exist, partially between organs, sometimes in the course of developmental processes, but most importantly between species and local variants. Notably, substantial variations were observed between specimens of the same or related species from habitats that differ with regard to temperature and light/UV exposure (cf. discussion in Hardeland et al., 2007b). It will be an important objective in the research of plant melatonin to understand why the levels of this compound can vary so profoundly and what the functional consequences of these divergencies are.

\section{IDENTITY OR DIFFERENCES IN PLANT MELATONIN METABOLISM?}

In plants, the classic pathway of melatonin biosynthesis from tryptophan comprises four steps, decarboxylation by tryptophan decarboxylase (TDC), hydroxylation of the amine by tryptamine 5 -hydroxylase $(\mathrm{T} 5 \mathrm{H})$ to serotonin, its $N$-acetylation by a serotonin $N$-acetyltransferase (SNAT), which catalyzes the same reaction as the nonhomologous aralkylamine $N$-acetyltransferase (AANAT) of vertebrates, and the final $O$-methylation to melatonin by $\mathrm{N}$-acetylserotonin $\mathrm{O}$-methyltransferase (ASMT, formerly known as hydroxymethyl O-methyltransferase, HIOMT). For summaries using the actual terminology see Tan et al. (2014b) and Hardeland (2015). Whether or not these enzymes are exclusively responsible for melatonin formation in plants may be not as certain as it appears at first glance.

The highly divergent melatonin levels of different plant species raise the question of whether this may be only caused by strongly deviating expression levels of the same biosynthetic enzymes. Alternately, this divergency may be explained by either (i) splice variants, (ii) homologous gene variants encoding enzymes that substantially differ with regard to substrate affinity and $V_{\max }$, (iii) deviating precursor availability, or (iv) the involvement of enzymes of only moderate homology. This latter possibility is not generally unlikely, since this has been also discussed for melatonin synthesis in extrapineal sites of vertebrates (Hardeland, 2008), despite the observation that AANAT and ASMT are responsible for melatonin formation in the pineal glands and various other organs in these animals. For instance, another $N$-acetyltransferase, NAT-1, was reported to contribute to melatonin synthesis in the mammalian skin (Slominski et al., 2005). In insects, several AANAT subforms exist, which strongly differ in their substrate specificity and are also involved in other functions such as exoskeleton sclerotization or neurotransmitter catabolism (Han et al., 2012; Barberà et al., 2013; Hiragaki et al., 2015). In the future, isoenzymes of melatonin biosynthesis should be more generally considered in the botanical area. Evidence for such isoenzymes has been recently summarized (Hardeland, 2015). In principle, these may be isoforms coded by the same or 
duplicated genes, but could also represent functionally deviating members belonging to the same protein family. In particular, a lower substrate specificity can be associated with side activities in the indoleamine metabolism, as will be illustrated below by the example of $\mathrm{O}$-methylation of $\mathrm{N}$-acetylserotonin in plants. On the other hand, relatively small genetic deviations, even point mutations, can profoundly change the substrate specificity within an enzyme family. Therefore, homologies in nucleotide or amino acid sequences should not be overinterpreted with regard to a possible involvement in melatonin formation, as recently illustrated for some examples from plants (Hardeland, 2015).

Alternate pathways may already exist for the formation of serotonin from tryptophan. Serotonin biosynthesis in plants is usually believed to be carried out by the sequential actions of TDC and $\mathrm{T} 5 \mathrm{H}$ and, therefore, to differ from the route in animals and dinoflagellates, which consists of tryptophan hydroxylation by a tryptophan 5-hydroxylase (TPH) followed by decarboxylation by an aromatic amino acid decarboxylase of usually broad substrate specificity (Hardeland, 2015). However, an animal-like pathway may be also present in some plant species. Although TDC and $\mathrm{T} 5 \mathrm{H}$ have been shown to be decisive for serotonin synthesis in both monocots and dicots, such as rice (Oryza sativa) (Byeon et al., 2014c) and apple (Malus $\times$ domestica) (Lei et al., 2013), the rice TDC was also reported to decarboxylate 5-hydroxytryptophan (Park et al., 2008). The T5H-deficient Sekiguchi rice cultivar produced elevated levels of 5-hydroxytryptophan (Park et al., 2012), a finding that demonstrates the existence of an additional tryptophan hydroxylase activity independent of $\mathrm{T} 5 \mathrm{H}$. However, this rice variant did not exhibit an increase in melatonin because the more strongly accumulating tryptamine efficiently competed with serotonin at the SNAT enzyme. Surprisingly, transcriptional silencing of $\mathrm{T} 5 \mathrm{H}$ in rice led to higher melatonin levels (Park et al., 2013a), a finding that, again, underlines the possibility of an alternate route of serotonin formation. Nevertheless, in rice, the classic plant pathway of TDC and $\mathrm{T} 5 \mathrm{H}$ is obviously of higher relevance, since TDC overexpression causes an increase in melatonin (Byeon et al., 2014c). This may not be necessarily the case in all other plant species. In Hypericum perforatum, the expression of a tryptophan 5hydroxylase was reported, in addition to TDC (He et al., 2012). Moreover, with reference to the statement made above that even point mutations can profoundly change the substrate specificity of some enzymes, it should be noted that the replacement of serine 372 by a glycine in the Papaver somniferum tyrosine decarboxylase generates a substantial affinity to 5-hydroxytryptophan (Torrens-Spence et al., 2014). In rice, three TDC isoforms were detected, TDC-1, TDC-2, and TDC-3, which seem to differ in their contribution to melatonin formation (Byeon et al., 2014c). The multiplicity of subforms and the general mutation-sensitive variability of substrate specificity observed in aromatic amino acid/amine decarboxylases (Torrens-Spence et al., 2013) may allow evolutionary changes in the serotonin pathway. Therefore, it may well be possible that, in some plants, the animal-type of serotonin formation has become prevalent. In the future, this should be particularly tested in plants that produce extremely high levels of melatonin.

Overexpression of TDC in rice leads to increased melatonin levels (Byeon et al., 2014c), a finding that indicates a rate limitation by the availability of tryptamine in this species. However, a second bottleneck in melatonin formation seems to exist in a number of plants, as can be deduced from the observation that serotonin concentrations are often by one or more orders of magnitude higher than those of melatonin, not only in the transgenic (Byeon et al., 2014c) but also in wildtype rice (Park et al., 2013d), in Datura metel (Murch et al., 2009), Punica granatum and Fragaria $\times$ ananassa (Badria, 2002). In these cases, especially when levels of $N$-acetylserotonin do not substantially exceed melatonin, SNAT seems to catalyze a secondary rate-limiting step, a situation reminiscent of vertebrate melatonin synthesis. However, this is not generally the case. In Echinacea purpurea, concentrations of serotonin and melatonin were in the same range (Jones et al., 2007). Serotonin contents that only moderately exceed those of melatonin may not substantially change the metabolic throughput in this pathway and seem to be a matter of variability between sibling species, strains and, perhaps, environmental differences of biotopes. For instance, serotonin concentrations did not substantially differ from those of melatonin in Vaccinium macrocarpon, but were almost five times higher in $V$. vitis-idaea (Brown et al., 2012). Notably, in several cases with very high melatonin contents, serotonin was reported to only moderately exceed the methoxyindole, such as in beans of Coffea canephora and C. arabica (serotonin 10.5 and $12.5 \mu \mathrm{g} / \mathrm{g}$; melatonin 5.8 and $6.8 \mu \mathrm{g} / \mathrm{g}$, respectively: Ramakrishna et al., 2012), or even to remain strongly below, such as in ripening wine grapes (serotonin about or lower than $10 \mu \mathrm{g} / \mathrm{g}$; melatonin between about 100 and $150 \mu \mathrm{g} / \mathrm{g}$ : Murch et al., 2010) and developing flowers of $H$. perforatum (serotonin maximally about $2 \mathrm{nmol} / \mathrm{g}$; melatonin maximally $4000 \mathrm{nmol} / \mathrm{g}$ : Murch and Saxena, 2002). Interestingly, the serotonin peak preceded that of melatonin in the Hypericum flower buds, whereas serotonin was practically undetectable in an early stage of Vitis grapes, although melatonin had already reached the range indicated. These findings strongly suggest that, in these high-melatonin tissues, $N$-acetylation of serotonin is not rate limiting. It would be of interest to study this more systematically and to test the possibility that a major difference between low- and high-melatonin plants may consist in the limitation or non-limitation of melatonin formation by SNAT activity, which might contribute to understanding why melatonin contents of plants can be so exceptionally divergent over many orders of magnitude.

Whether or not the deduced divergencies of SNAT activity may be associated with differently regulated subforms or the involvement of nonhomologous serotonin-acetylating enzymes is unknown. Pertinent information is still restricted to a very few species and most molecular data are from rice (cf. Hardeland, 2015). Recently, a SNAT from A. thaliana had been cloned (Lee et al., 2014b) and another one from a gymnosperm, Pinus taeda (Park et al., 2014). SNAT from Oryza sativa displays homology to a cyanobacterial enzyme and is, in line with this information, plastidially located (Byeon et al., 2013, 2014b). However, its 
vertebrate paralog, AANAT, is of alphaproteobacterial origin and thought to be inherited via mitochondria (Tan et al., 2013). To date, there is no existing evidence for mitochondrial serotonin acetylation in plants by an AANAT-like enzyme, but, on the small basis of respective knowledge, this should not yet be ruled out.

The final step of melatonin formation is catalyzed by cytosolic members of plant $O$-methyltransferases, which display differences to the mammalian ASMT (Park et al., 2013c) and do not seem to be closely related to the vertebrate enzymes. Obviously, several enzymes from plants are capable of catalyzing the $\mathrm{O}$-methylation of $\mathrm{N}$-acetylserotonin. In rice, three isoforms, ASMT1, ASMT2, and ASMT3 were reported to be encoded by different genes (Park et al., 2013b). In addition to these enzymes, ASMT activity was shown to be present in Arabidopsis caffeic acid $\mathrm{O}$-methyltransferase (COMT). This activity was not negligible, although the nominal substrate, caffeic acid, displayed a higher affinity than $\mathrm{N}$-acetylserotonin (Byeon et al., 2014a). Recently, O. sativa COMT was shown to methylate $N$-acetylserotonin at a 609-fold rate compared to ASMT1 from this species. Moreover, it was possible to increase or decrease melatonin synthesis in rice by overexpressing or suppressing OsCOMT (Byeon et al., 2015a). Nevertheless, it remains to be clarified to which degree other, competing substrates may reduce the ASMT-like activity of physiological OsCOMT levels. The situation seems to be entirely different in Arabidopsis, in which the specificity balance of COMT was anyway strongly on the side of caffeic acid. In fact, a recent study reported cloning and characterization of an AtASMT devoid of COMT activity (Byeon et al., 2016). However, this enzyme also methylated efficiently serotonin to 5-methoxytryptamine (5-MT), a finding that indicates the possible existence of an inverse route of melatonin formation, in which serotonin is first O-methylated and 5-MT, which is also accepted by SNAT, subsequently $N$-acetylated. Both routes, the traditional and the inverse one, may be used in parallel, as had been previously shown in Saccharomyces, in which melatonin can be formed from either $\mathrm{N}$-acetylserotonin or 5MT (Sprenger et al., 1999). According to the recent publication on AtASMT, ASMT-like sequences had been also detected in various other monocot and dicot species, however, with relatively low homology. An ASMT from M. zumi was cloned, characterized and also expressed in A. thaliana (Zuo et al., 2014). Overexpression of the transgene caused two to fourfold rises of melatonin in A. thaliana. With regard to the divergent findings on ASMT activities, three main conclusions should be drawn. (1) There may be considerable differences between species concerning the $\mathrm{O}$-methyltransferases involved. These deviations may contribute to the remarkable differences in the melatonin levels detected in the various species. (2) The possibility of further enhancing melatonin formation by overexpressing ASMT transgenes indicates that ASMT activity can become rate limiting under certain conditions. This should not be seen as an unual exception, since this is also known from mammals, in which AANAT is limiting at low or moderately elevated rates of melatonin synthesis, whereas ASMT can become limiting at highest rates of melatonin formation (Liu and Borjigin, 2005). (3) The variable substrate affinity and sometimes low specificity of O-methyltransferases should be taken as a caveat for not precociously concluding from partial homology on functional identity.

In plants, the understanding of catabolic melatonin metabolism is still in its infancy. From a general point of view, enzymatic and nonenzymatic routes of catabolism have to be distinguished. Nonenzymatic reactions with free radicals or singlet oxygen should be similar as in animals, but may be even more important, with regard to higher rates of oxidant generation in plants and more intense and poorly protected light exposure.

An overview of nonenzymatic hydroxylation (Tan et al., 2002) and dioxygenation reactions has been included in a recent review article (Hardeland, 2015). Nonenzymatic hydroxylations in different positions of the indole moiety are caused by interactions with free radicals of higher reactivity, usually hydroxyl radicals $(\cdot \mathrm{OH})$, e.g., by sequential actions of either two $\cdot \mathrm{OH}$ or another hydrogen-abstracting radical followed by combination with $\cdot \mathrm{OH}$. Among the hydroxylated products, a metabolite carrying a third ring should be especially mentioned, cyclic 3-hydroxymelatonin (Figure 1), which is formed nonenzymatically in animal tissues under conditions of oxidative stress and displays, reminiscent of the parent compound, properties of an antioxidant (Tan et al., 1998, 2014a). Nonenzymatic dioxygenation of melatonin is mostly caused by sequential actions of an electron/hydrogenabstracting free radical and a superoxide anion (Hardeland et al., 2003) or by interaction with a singlet oxygen (de Almeida et al., 2003). During dioxygenation, the pyrrole ring is cleaved to give a substituted kynuramine, $N^{1}$-acetyl- $N^{2}$-formyl5-methoxykynuramine (AFMK; Figure 1). Further possibilities including pseudoenzymatic and photocatalytic reactions that lead to the same metabolite have been summarized elsewhere (Hardeland et al., 2009). AFMK can be also formed from cyclic 3-hydroxymelatonin by interaction with two $\cdot \mathrm{OH}$. Reactions of AFMK with free radicals can lead to the formation of numerous other metabolites (Rosen et al., 2006; Hardeland et al., 2009), which have, however, not yet been studied in plants.

With regard to enzymatic melatonin catabolism, several possibilities known from animals and other eukaryotes may exist, such as hydroxylations, demethylation, deacetylation, and dioxygenation. Because of the high numbers of cytochrome $\mathrm{P}_{450}$ (CYP) isoforms present in plants (Paquette et al., 2000; Zhong et al., 2002), hydroxylations and demethylation are highly likely. Among these possibilities, to date only one hydroxylation reaction has been detected, which was, however, not attributed to CYP enzyme, but rather to a melatonin 2-hydroxylase (M2H; Byeon et al., 2015b). M2H belongs to the 2-oxoglutarate-dependent dioxygenases (2-ODDs), which transfer the second $\mathrm{O}$-atom to 2-oxoglutarate, which, thereafter, decomposes to succinate and $\mathrm{CO}_{2}$. Its gene from rice has been cloned and four different 2-ODD proteins were detected and shown to 2-hydroxylate melatonin (Byeon and Back, 2015). In plants, the $\mathrm{M} 2 \mathrm{H}$ route seems to be of much higher importance than any other catabolic pathway of melatonin. In numerous plants such as rice, various dicots and also two gymnosperms, 2-hydroxymelatonin exceeded the melatonin levels, often by far (Byeon et al., 2015c). Notably, 2-hydroxymelatonin enters a tautomeric equilibrium 


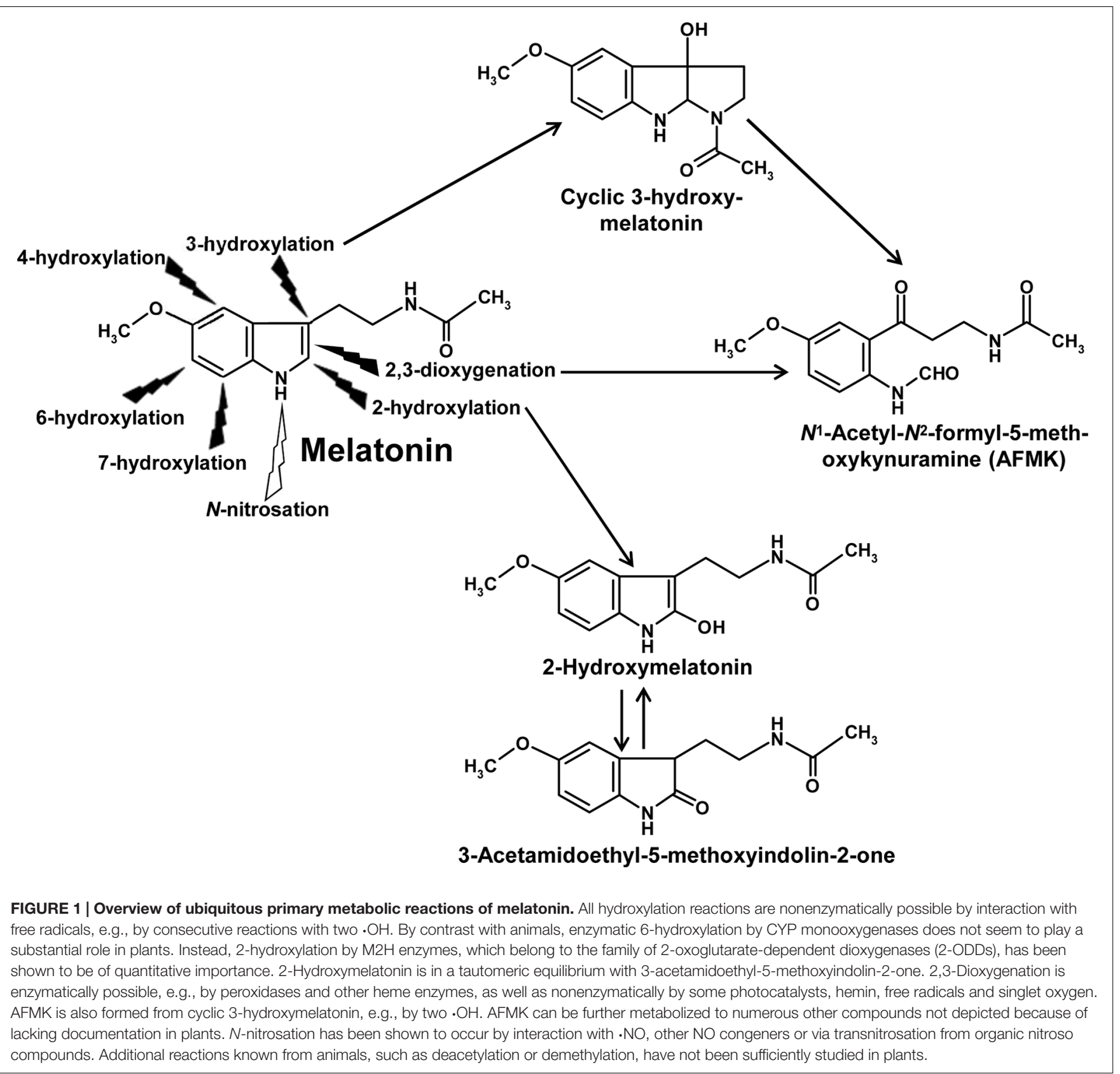

with the relatively stable 3-acetamidoethyl-5-methoxyindolin-2one (Figure 1), which can be easily detected in chromatograms containing the 2-hydroxylated metabolite (Hardeland, 2010). This indolinone is much more lipophilic than its tautomer, 2hydroxymelatonin. Therefore, it might be of interest to find out whether the very high amounts of the latter compound may be related to the entrance of the indolinone into lipophilic compartments or into vacuoles in which a further metabolization is less likely, but from which 2-hydroxymelatonin may be tautomerically regenerated. The presence and functional capacity of $\mathrm{M} 2 \mathrm{H}$ enzymes represents a major difference to melatonin catabolism in animals. With regard to the high levels of 2hydroxymelatonin, it may be important to seek for eventual physiological roles of this compound or, alternately, to identify it as waste molecule.

Apart from this metabolite, only one hydroxylated product of melatonin was to date discovered in plants, namely 4hydroxymelatonin, which made up not more than $0.05 \%$ of these metabolites, whereas 6-hydroxymelatonin, the major metabolite in animals, remained below the detection threshold (Byeon et al., 2015c). Dealkylation by CYP isoforms, which is a rather common reaction type of these enzymes, has not yet been documented in plants, perhaps, because researchers did not study this directly, and since the resulting product $N$-acetylserotonin would not have been distinguished from the same molecule as a precursor. Deacetylation of melatonin to 5-MT, another bioactive metabolite 
known from animals and also from phototrophic dinoflagellates (Hardeland et al., 1997, 2007b; Hardeland, 1999), has not yet been studied in plants. However, as mentioned above, 5-MT can be formed from serotonin by AtASMT (Byeon et al., 2016).

Enzymatic formation of the dioxygenated product, AFMK, has been shown to exist in rice, in which an indoleamine 2,3dioxygenase (IDO) carrying out this reaction was identified and cloned. Upon overexpressing it as a transgene in tomatoes, melatonin levels were reported to decrease (Okazaki et al., 2010). This may indicate a certain physiological role of enzymatic AFMK formation, although the quantitative relevance cannot yet be easily judged. Quantification of AFMK in plant tissues was convincingly carried out in Eichhornia crassipes (Tan et al., 2007). Under natural light/dark conditions, the compound exhibited a 24-h rhythm with a maximum around the transition from phototo scotophase, roughly in parallel with a rhythm of melatonin in this species. However, it is not yet clear to which extent this was due to an IDO and whether photochemical reactions, e.g., by singlet oxygen, contributed to the increase of AFMK over the photophase.

\section{AUXIN-LIKE EFFECTS}

Morphogenetic and growth effects of melatonin, which comprise auxin-like actions, have been fully or partially reviewed a number of times in the last years (Arnao and Hernández-Ruiz, 2006, 2014, 2015; Paredes et al., 2009; Tan et al., 2012; Arnao, 2014; Hardeland, 2015). These observations have been made in various different species, both monocots and dicots, and different test systems, such as poacean coleoptiles (Phalaris, Triticum, Avena, Hordeum), Lupinus hypocotyls, root growth and formation or regeneration of adventitious and lateral roots (Oryza, Lupinus, Prunus, Arabidopsis, Brassica), and shoot multiplication by nodal segments (Mimosa), as recently summarized (Hardeland, 2015). Notably, concentration differences for stimulatory or inhibitory effects in roots, as known from auxins, were also observed with melatonin.

Although, in phenomenological terms, the auxin-like effects are well documented, the mechanistic understanding of melatonin's actions is still insufficient. The structural differences between the indolic compounds melatonin and indole 3-acetic acid (IAA) are too pronounced to assume affinity to the same binding sites. Indirect effects of melatonin on IAA levels have been reported, but did not reveal consistent changes. In Brassica juncea, $0.1 \mu \mathrm{M}$ melatonin elevated the IAA concentration in roots (Chen et al., 2009). However, overexpression of an ovine AANAT transgene in 'Microtom' tomato plants caused an increase in melatonin, but a reduction in IAA that was associated with a loss of apical dominance (Wang et al., 2014b). Therefore, melatonin is not just a stimulator of IAA formation, but the actions of the two signal molecules can be dissected. However, the inverse correlation between melatonin and IAA observed in tomato may not necessarily reflect a physiological relationship, if the melatonin and IAA biosynthetic pathways compete for precursors and AANAT overexpression favors the former. However, this assumption would require direct experimental support. Another theoretically possible explanation might have been a catabolic route from melatonin via 5-MT and 5-methoxyindole 3-acetaldehyde to the auxin 5-methoxyindole 3 -acetic acid, a pathway that exists in phototrophic dinoflagellates and animals (Hardeland et al., 2007b). However, this was ruled out in plants for reasons of product quantities (Arnao and Hernández-Ruiz, 2006). To date, it seems that the actions of melatonin and auxins are transmitted by different signal transduction pathways, which finally converge at some but not necessarily all regulatory checkpoints. The involvement of cytosolic calcium in both melatonin and IAA signaling, as recently discussed (Hardeland, 2015), would require further in-depth elaboration of mechanistic details. Differences in the actions of melatonin and auxins may be overlooked when studying a single or a very few growth-related or morphogenetic endpoints. In A. thaliana, melatonin as well as IAA and another auxin stimulated lateral root formation, but melatonin did not enhance the expression of an auxin-dependent GUS reporter (Koyama et al., 2013). An even more conflicting result was obtained in a transcriptome analysis of A. thaliana, according to which the genes of auxin signaling were preferentially downregulated by melatonin (Weeda et al., 2014). Under the impression of these findings, the auxin-like actions of melatonin appear more enigmatic than before. Another theoretical possibility is still devoid of direct experimental support and also seems to conflict with the transcriptome data. Melatonin was shown to downregulate IAA17 (indole-3-acetic acid inducible 17, alias auxin resistant 3, AXR3; Shi et al., 2015d), which acts as transcriptional repressor of various auxin-inducible genes. Therefore, melatonin might indirectly cause upregulations of auxin-dependent genes and, thus, cause effects known from IAA. However, these melatonin effects had been observed in the context of leaf senescence and may not be generally applicable.

Under the aspect of the highly divergent melatonin concentrations measured in plants, it should be underlined that relatively low concentrations of melatonin are required for auxin-like actions. This is precisely what one would expect from a signal molecule. The problem that arises is rather that of the role of melatonin in those species, their organs or seeds, which contain by orders of magnitude higher concentrations of melatonin. If, in these high-melatonin plants or parts thereof, melatonin were freely diffusible, regulation mechanisms based on high-affinity binding sites would no longer be functional, because of a persistent full saturation or even saturationdependent desensitization. Therefore, the alternative seems to be that either melatonin is not freely diffusible, but sequestered by proteins, absorbed by oil droplets, perhaps otherwise hindered to leave certain compartments, or regulation mechanisms working at low concentrations are switched off. In the latter case, auxin-like effects of melatonin should not be expected.

The observation of growth inhibition at elevated levels of melatonin, especially in roots, has been forwarded as another argument for an auxin-like action. However, despite the similarity to the concentration dependence of auxin effects, this conclusion may not be entirely firm, because elevated levels of melatonin can interfere with the cytoskeleton including the mitotic spindle. 
This is known from the earliest studies of melatonin in plants, in endosperm cells of Scadoxus multiflorus (syn. Haemanthus katherinae; Jackson, 1969) and onion roots of Allium cepa (Banerjee and Margulis, 1973).

\section{STRESS AND SENESCENCE}

Melatonin effects in the complex of biotic and abiotic stress, defense, wound healing and senescence represent an emerging field, which seems to receive increasing attention. Notably, the transcriptome analysis by Weeda et al. (2014), which revealed down- rather than upregulations of auxin-related pathways in A. thaliana, demonstrated various stimulatory actions of melatonin on the pathways of ethylene, abscisic, jasmonic, and salicylic acids. However, in the context of stress, melatonin was also reported to conversely downregulate formation and upregulate catabolism of abscisic acid in Malus species (Li et al., 2015). In addition to the effects that seem to be mediated by these phytohormones, the role of melatonin as an antioxidant may play an additional role that could be in favor of stress resistance, healing and survival. In this regard, the situation is reminiscent of that in animals and comprises reduction of oxidant formation, direct scavenging of oxidants as well as induction of antioxidant enzymes and support of favorable redox balances of other antioxidants such as glutathione (Kostopoulou et al., 2015; Li et al., 2015; Shi et al., 2015f). This parallel to animals, which is not equally detectable in other functions of melatonin, might be seen as a consequence of a most ancient antioxidant role of melatonin (Hardeland et al., 1995), which is already demonstrable in unicellular organisms (Antolín et al., 1997) and includes mechanisms that reduce free-radical formation (Hardeland, 2005).

The complex of stress resistance, healing, and senescence has been fully or partially reviewed in recent publications (Arnao and Hernández-Ruiz, 2014, 2015; Hardeland, 2015; Zhang et al., 2015) or extensively addressed (Shi et al., 2015f). Instead of repeating in detail the findings summarized there, only their essence shall be briefly outlined, followed by a focus on the most recent results. A remarkable observation has been that the various forms of environmental or biotic influences that may be interpreted as stress typically lead to increases in melatonin (Figure 2). This includes extreme temperatures - both cold stress and heat stress -, intense radiation, drought, high salinity, and chemical stressors such as hydrogen peroxide, $\mathrm{ZnSO}_{4}$ or herbicides (for details see Arnao and Hernández-Ruiz, 2009b, 2013, 2014, 2015; Arnao, 2014; Hardeland, 2015; Zhang et al., 2015), and also exposure to a bacterial pathogen (Qian et al., 2015; Shi et al., 2015a). The rises in melatonin, caused by entirely different factors, may be indicative of its involvement in a fundamental stress resistance mechanism. Most of these observations had been made in various plant species, dicots and monocots. Increases of melatonin have been particularly described as a consequence of UV radiation, which will be discussed in the following section on photoprotection.

With regard to the complex of stress responses, as induced by various abiotic or biotic factors, of wound healing and leaf senescence, there is a considerable overlap of actions by several pertinent phytohormones, such as ethylene, abscisic, salicylic, and jasmonic acids/methyl jasmonate (Jibran et al., 2013; Khan et al., 2014), and also in their nexus with melatonin (Hardeland, 2015). This view is in line with the observation that melatonin supports the resistance to different forms of stress caused by factors as divergent as drought, cold, heat, osmotic stress, oxidative stress (Chan and Shi, 2015; Shi et al., 2015b ) and also by bacterial pathogens (Shi et al., 2015a). Despite these similarities, the factors influenced by melatonin can be different according to the type of challenge. Nevertheless, joint pathways and response types do exist, especially in the cases of cold and drought stress. Moreover, it has to be noted that many forms of stress are associated with increased oxidative damage. Therefore, the antioxidant actions of melatonin appear to be a common theme of stress management in plants, a conclusion that has been similarly applied to many animals.

Among the most recent developments in this field of plant responses, a considerably increased number of studies has been conducted in Arabidopsis. With regard to an improved cold tolerance by melatonin, the overlap with drought resistance has become obvious by the induction of transcription factors involved in either of these responses, in particular, CAMTA1, $C B F 1, C B F 2 a, C B F 2 b, C B F 3 a$, and $C B F 3 b$ (Bajwa et al., 2014). Moreover, the cold-responsive genes COR15a, RD22, and KIN1 (Bajwa et al., 2014; Shi et al., 2015c) as well as the oxidant-induced zinc-finger transcription factors ZAT10 and ZAT12 were upregulated by melatonin. The connection between cold tolerance and avoidance of oxidative damage was further confirmed and focused on another zinc-finger protein, ZAT6 (Shi and Chan, 2014). Knockdown of the ZAT6 gene reduced the melatonin-mediated cold resistance, whereas ZAT6 overexpression enhanced it. Additionally, melatonin was shown to upregulate ZAT6 as well as $C B F 1, C B F 2$, and $C B F 3$.

In the case of heat stress, other signaling pathways are, expectably, involved. In Arabidopsis, melatonin was recently shown to upregulate class A1 heat shock factors (HSFA1s). HSFA1-inducible genes such as HSFA2s, HSA32 (heat stressassociated 32), HSP90, and HSP101 are assumed to participate in the increased thermotolerance conveyed by melatonin (Shi et al., 2015e). With regard to other forms of stress, drought resistance was shown to be enhanced in Arabidopsis by overexpression of an ASMT transgene from M. zumi and, thus, by enhanced melatonin synthesis (Zuo et al., 2014). Another aspect of drought tolerance was investigated in M. hupehensis (Li et al., 2015). In this study, the antioxidant capacity of melatonin was demonstrated by decreases of $\mathrm{H}_{2} \mathrm{O}_{2}$ levels, in conjunction with upregulations of catalase and peroxidases. Some minor increases in ascorbate peroxidase (APX) were also reported, which were, however, more pronounced in M. prunifolia, a species with higher natural drought tolerance. Additionally, the protective effects of melatonin were associated with increased stomatal aperture and moderate improvements of photosynthesis. In Glycine max, melatonin enhanced both drought resistance and salt tolerance, in conjunction with a reversal of salt-induced reductions in the expression of numerous genes (Wei et al., 2015). Increased salt tolerance was also recently demonstrated in 


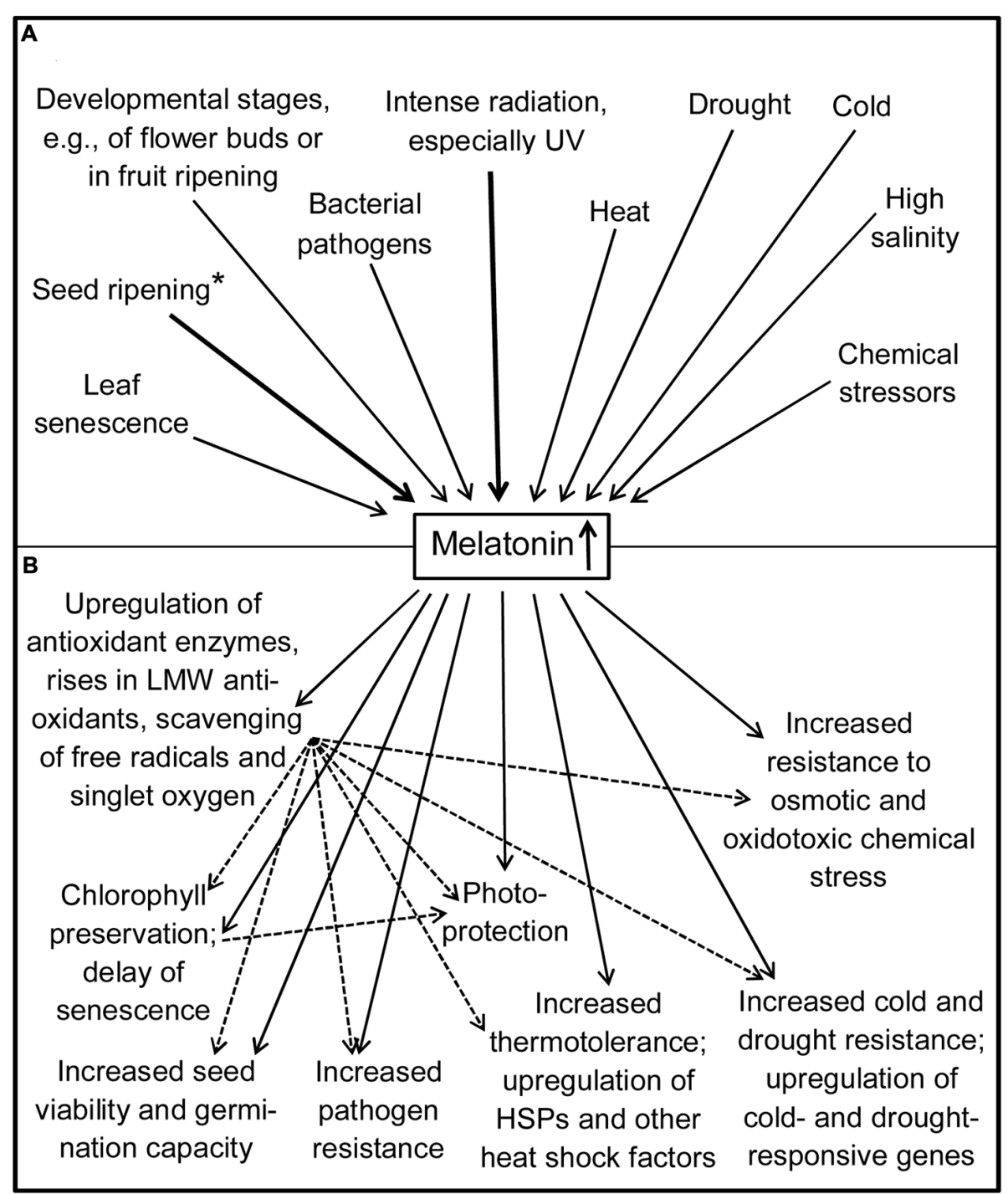

FIGURE 2 | Increases in melatonin (A) and their consequences for protection and stress tolerance (B). Bold arrows: particularly strong accumulations of melatonin. Dotted arrows: secondary effects via antioxidative protection. *Melatonin may be more strongly taken up than synthesized on-site. HSP, heat shock protein; LMW, low-molecular weight. Some actions may be species-specific or conditional.

O. sativa (Liang et al., 2015) and in seedlings of Citrus aurantium (Kostopoulou et al., 2015). In the latter case, combinations of melatonin and ascorbic acid were tested, which increased the levels of several low molecular-weight antioxidants and activities of antioxidant enzymes. As in this study, many of the recent investigations revealed a causal relationship between exogenous stress factors and induction of oxidative stress and damage, which were mitigated by melatonin (cf. Figure 2). This was especially observed in dicots such as Arabidopsis (Shi and Chan, 2014) and Malus (Li et al., 2015), and monocots such as Cynodon (Shi et al., 2015b,f) and Oryza (Liang et al., 2015). For further details reviewed earlier see Tan et al. (2012). In Cynodon, melatonin was shown to reduce reactive oxygen species and lipid peroxidation (Shi et al., 2015b). In Oryza, an $\mathrm{H}_{2} \mathrm{O}_{2}$-overproducing mutant, noe1, was also tested, in which melatonin protected against accelerated leaf death (Liang et al., 2015). This finding may be also seen in the context of normal leaf senescence, since melatonin reduced chlorophyll degradation and suppressed senescenceassociated genes. Protection by melatonin against losses of chlorophyll and delay of senescence appear to be a common theme in plants (for further details and mechanistic aspects see: Hardeland, 2015). Among the most recent investigations, the effects of melatonin on gene expression during leaf senescence, as revealed by a proteomic approach, should be mentioned (Wang et al., 2014a), and also a study in Arabidopsis on the relationship to IAA17 (Shi et al., 2015d). While IAA17 overexpression caused advanced senescence, melatonin downregulated this gene as well as the levels of SEN4 (senescence 4) and SAG12 (senescence-associated gene 12) mRNAs, thereby decelerating senescence. 
The reduction of oxidative stress by melatonin has been recently investigated in the context of phytotoxic agents. In Arabidopsis treated with paraquat (=methyl viologen), melatonin upregulated APX and catalase, however, without substantially altering the production of superoxide and $\mathrm{H}_{2} \mathrm{O}_{2}$ under the influence of the oxidotoxin. Instead, melatonin promoted autophagy, which may be interpreted as a survival strategy to eliminate the oxidatively damaged organelles (Wang et al., 2015). In Solanum lycopersicum, cadmium toxicity was reduced by melatonin (Hasan et al., 2015). This was not restricted to the upregulation of antioxidant enzymes, but also included metal sequestration by phytochelatins and elimination of cadmium from the cytosol by transfer to the cell wall and to the vacuole.

Particular attention has been recently paid to actions of melatonin under conditions of biotic stress. This has been mainly studied in Arabidopsis, occasionally also in Nicotiana, using the pathovar tomato DC3000 of Pseudomonas syringae. First, melatonin was shown to upregulate pathogen-related, salicylic acid- and ethylene-dependent genes, effects that were suppressed in mutants defective in salicylic acid and ethylene signaling, such as npr1, ein2, and mpk6 (Lee et al., 2014a). Next, SNAT knockouts did not only exhibit reduced levels of melatonin, but also of salicylic acid, along with a higher susceptibility to the pathogen (Lee et al., 2015). Infection with this pathogen caused rises in both melatonin and nitric oxide, while melatonin itself increased NO and salicylic acid-related genes, in conjunction with a reduced susceptibility (Shi et al., 2015a). Further studies revealed a relationship of melatonin to sugars that may also contribute to the thickness and resistance of cell walls (Zhao et al., 2015b). More detailed analyses (Qian et al., 2015) showed that melatonin enhanced the levels of various sugars, including glucose, fructose, sucrose, and melibiose, as well as that of glycerol, effects that were also elicited by the infection. Administration of fructose, glucose, sucrose, or glycerol increased pathogen resistance in wildtype plants, but not so in the salicylic acid-deficient NahG strain and in two NO-deficient mutants, noa1 and nia1nia2. Moreover, the sugars and glycerol caused rises in NO but not in melatonin. In conclusion, melatonin seems to be involved in innate plant immunity as a factor that acts upstream of salicylic acid and NO, while rises in sugars and glycerol stimulate NO formation. With regard to the reduced resistance in SNAT knockouts, a full stimulation of immunity likely requires upregulation of melatonin synthesis.

\section{PHOTOREACTIONS AND PHOTOPROTECTION}

In the context of increased levels of melatonin and protection conveyed by this compound, most publications on exposure to high light intensities and especially UV have discussed this as just one of various forms of stress. However, there are several peculiarities that seem to exceed a more generalized stress response. First, the extent of UV-induced rises in melatonin is, in many cases, remarkably large. Alpine or Mediterranean species or varieties, which are exposed to high natural light and UV intensities, were shown to contain considerably higher melatonin levels than the same or related species from other habitats (Conti et al., 2002; Caniato et al., 2003; Hardeland et al., 2007b). Conti et al. (2002) published data of nine Alpine or Mediterranean plants with levels of $10-43 \mu \mathrm{g}$ melatonin/g tissue. In fruits of an Egyptian Fragaria cultivar, high vis/UV light exposure was reported to increase melatonin (Badria, 2002). In leaves of the pontederiacean E. crassipes, melatonin levels were considerably higher (up to $300 \mathrm{ng} / \mathrm{g}$ fresh weight) in plants directly collected from a pond (maximal diurnal irradiation $10,000-15,000 \mu \mathrm{W} / \mathrm{cm}^{2}$ ) than those (ca. $3 \mathrm{ng} / \mathrm{g}$ ) from laboratory conditions (400-450 $\mu \mathrm{W} / \mathrm{cm}^{2}$; Tan et al., 2007). Presumably, this increase has included effects by UV, but the contribution of a temperature cycle in the natural environment cannot be ruled out. An aspect that speaks for a role of radiation and, perhaps, also for a photoprotective function of melatonin concerns the observed increase of melatonin in the course of the photophase, with a maximum around the transition to the scotophase. Notably, the diurnal change in melatonin concentration was accompanied by a corresponding rhythm in AFMK formation (Tan et al., 2007). As mentioned at the end of the section on metabolism, a contribution of indoleamine 2,3-dioxygenase to this rhythm cannot be excluded. However, melatonin is known to undergo several photocatalytically mediated reactions including dioxygenation (Behrmann et al., 1997; Hardeland et al., 2007b). Light-exposed extracts from phototroph organisms, such as the dinoflagellate L. polyedrum and the pheophycean Pterygophora californica, converted melatonin efficiently to AFMK, even in the presence of the hydroxyl radical scavenger DMSO (Hardeland et al., 1995; Behrmann et al., 1997). Among known light-induced reactants, melatonin is, in particular, oxidized by singlet oxygen to AFMK (de Almeida et al., 2003; Schaefer and Hardeland, 2009). The photoproduct AFMK is relatively inert against singlet oxygen and can, therefore, accumulate under these conditions. However, its secondary, deformylated metabolite, $N^{1}$-acetyl-5methoxykynuramine (AMK), which may be formed in plants enzymatically or by interactions with free radicals, is, among low molecular weight metabolites, one of the most efficient singlet oxygen quenchers detected, more potent than melatonin or histidine (Schaefer and Hardeland, 2009), and additionally an effective scavenger of various reactive oxygen and nitrogen species (Ressmeyer et al., 2003; Guenther et al., 2005; Hardeland et al., 2007a).

A presumed role of melatonin and, perhaps, its metabolites in photoprotection of plants would also be in line with the observed protection against chlorophyll degradation (Arnao and Hernández-Ruiz, 2009a; Tan et al., 2012; Wang et al., 2012, 2013), although this has certainly also to be seen under additional aspects of chlorophyll $\mathrm{a} / \mathrm{b}$ binding protein (CAB) expression, delayed upregulation of pheophorbide a oxygenase (Wang et al., 2013) as well as stress- and senescence-related signaling.

However, the assumed photoprotection of plants should not be generalized. In Glycyrrhiza uralensis, exposure to visible or UV-B light caused rises in melatonin, but mainly in the roots (Afreen et al., 2006), a response that should rather be interpreted as a stress response. Moreover, high light intensities do not 
generally favor an elevation of melatonin. In Oryza sativa, a heatinduced increase was antagonized by light (Byeon and Back, 2014).

A further aspect, which merits more future attention, concerns the concentration dependence of protection. Very high melatonin levels in leaves, as sometimes observed in strongly UV-exposed plants (Conti et al., 2002; Caniato et al., 2003), may allow nonenzymatic elimination of free radicals and singlet oxygen at substantial rates, in addition to the anyway effective antioxidative protection system based on ascorbate, glutathione, APX, glutathione peroxidase (GPX) and other compounds. Moreover, two properties of melatonin should be considered, namely, a nonadditive synergistic interaction of melatonin and other antioxidants, notably, ascorbate and glutathione (Tan et al., 2003) and melatonin's scavenger cascade, which allows elimination of up to 10 free radicals per melatonin molecule by formation of consecutively formed metabolites with scavenging properties (Rosen et al., 2006). The highly divergent levels of melatonin found in different plant species may allow, in some of them, a substantial contribution to nonenzymatic protection, whereas, in other species containing this compound in much lower concentrations, actions are restricted to signaling mechanisms. The background of this divergence may be sought in unfavorable physiological effects of elevated melatonin in certain species. Such a case was recently reported. In Zea mays, low doses of melatonin favored photosynthesis and nocturnal starch catabolism, whereas high doses caused the opposite, downregulated sucrose transporter expression and inhibited seedling growth (Zhao et al., 2015a). In conclusion, physiologically relevant differences in melatonin tolerance may exist between plant species.

\section{CONCLUSION}

During the last years, considerable progress has been made in melatonin research in plants. This does not only concern the extension of knowledge on its presence in an increasing number of species and taxa, but also the identification of metabolic pathways and a remarkable amount of new information on the involvement in physiological functions. Nevertheless, there is still a strong demand for clarification of several fundamental points.

One of these is related to the enormous differences in the melatonin content of different species and organs. As already outlined in the Introduction, signaling mechanisms based on high-affinity binding sites for melatonin cannot be expected to work at strongly elevated concentrations that would permanently saturate a binding protein. However, this aspect of divergent concentrations requires a distinction between metabolically active and dormant tissues. In the case of extremely high melatonin levels in leaves, signaling mechanisms known from low-melatonin species may not be functional. Alternately, one would have to assume either different mechanisms based on lowaffinity instead of high-affinity binding sites or a sequestration of melatonin in areas of limited metabolic activity, such as the vacuole or the apoplast. The necessity of determining the distribution of melatonin within the tissue (Hardeland, 1997) might resolve some concentration-related discrepancies that appear rather enigmatic to date. An additional possibility of removing melatonin from the cytosol might consist in its uptake into oil bodies, which has been shown to occur in sunflower seedlings (Mukherjee et al., 2014). Moreover, this could be of particular importance in oily seeds. High melatonin levels in seeds of various plants are well documented (Manchester et al., 2000). A more or less dry, dormant seed is practically devoid of enzymatic antioxidative protection and has, therefore, to rely on low molecular-weight antioxidants (Balzer and Hardeland, 1996; Hardeland et al., 2007b), among which melatonin has a number of advantages. Moreover, melatonin might contribute to the maintenance of the dormant state and to the survival in dormancy (Balzer and Hardeland, 1996; Hardeland et al., 2007b), at least by reducing oxidative damage, which limits the germination potential of seeds. In fact, the preservation of seed viability by applying high concentrations of exogenous melatonin has been recently demonstrated in Arabidopsis (Hernández et al., 2015). In rehydrated seeds, melatonin may promote seed germination, especially under unfavorable conditions. This view is supported by recent findings in seeds of Cucumis sativus under high salinity (Zhang et al., 2014). Support of germination was also reported for the negatively photoblastic seeds of Phacelia tanacetifolia, but interpreted, in this case, as a mimicking of darkness by melatonin (Tiryaki and Keles, 2012).

Another aspect that awaits further clarification concerns the role of isoenzymes in the melatonin biosynthetic pathway, as outlined in the section on metabolism. More specifically, the contribution of different isoenzymes to the highly divergent melatonin levels detected in different species should be elucidated.

The field in which progress is most urgently required is that of signaling pathways. Although the influence of melatonin on gene expression otherwise known to be controlled by phytohormones has been amply documented by transcriptomic and proteomic analyses, primary signaling mechanisms by melatonin have remained entirely unexplored. With regard to the cytoskeletal effects, binding of melatonin to calmodulin may occur, as known from animals, but has not been directly demonstrated. However, high-affinity binding sites of melatonin and their properties are still unknown in plants. In the absence of their identification, no information can be obtained on receptor-mediated signal transduction and second messengers involved in the modulation of actions of established phytohormones and gene regulation. Progress in this field may be critical to the possible classification of melatonin as a phytohormone.

\section{AUTHOR CONTRIBUTIONS}

The author confirms being the sole contributor of this work and approved it for publication. 


\section{REFERENCES}

Afreen, F., Zobayed, S. M. A., and Kozai, T. (2006). Melatonin in Glycyrrhiza uralensis: response of plant roots to spectral quality of light and UV-B radiation. J. Pineal Res. 41, 108-115. doi: 10.1111/j.1600-079X.2006.00337.x

Antolín, I., Obst, B., Burkhardt, S., and Hardeland, R. (1997). Antioxidative protection in a high-melatonin organism: the dinoflagellate Gonyaulax polyedra is rescued from lethal oxidative stress by strongly elevated, but physiologically possible concentrations of melatonin. J. Pineal Res. 23, 182-190. doi: 10.1111/j.1600-079X.1997.tb00353.x

Arnao, M. B. (2014). Phytomelatonin: discovery, content, and role in plants. $A d v$. Bot. 2014:815769. doi: 10.1155/2014/815769

Arnao, M. B., and Hernández-Ruiz, J. (2006). The physiological function of melatonin in plants. Plant Signal. Behav. 1, 89-95. doi: 10.4161/psb.1.3.2640

Arnao, M. B., and Hernández-Ruiz, J. (2009a). Protective effect of melatonin against chlorophyll degradation during the senescence of barley leaves. J. Pineal Res. 46, 58-63. doi: 10.1111/j.1600-079X.2008.00625.x

Arnao, M. B., and Hernández-Ruiz, J. (2009b). Chemical stress by different agents affects the melatonin content of barley roots. J. Pineal Res. 46, 295-299. doi: 10.1111/j.1600-079X.2008.00660.x

Arnao, M. B., and Hernández-Ruiz, J. (2013). Growth conditions determine different melatonin levels in Lupinus albus L. J. Pineal Res. 55, 149-155. doi: 10.1111/jpi.12055

Arnao, M. B., and Hernández-Ruiz, J. (2014). Melatonin: plant growth regulator and/or biostimulator during stress? Trends Plant Sci. 19, 789-797. doi: 10.1016/j.tplants.2014.07.006

Arnao, M. B., and Hernández-Ruiz, J. (2015). Functions of melatonin plants: a review. J. Pineal Res. 59, 133-150. doi: 10.1111/jpi.12253

Badria, F. A. (2002). Melatonin, serotonin, and tryptamine in some Egyptian food and medicinal plants. J. Med. Food 5, 153-157. doi: 10.1089/10966200260398189

Bajwa, V. S., Shukla, M. R., Sherif, S. M., Murch, S. J., and Saxena, P. K. (2014). Role of melatonin in alleviating cold stress in Arabidopsis thaliana. J. Pineal Res. 56, 238-245. doi: 10.1111/jpi.12115

Balzer, I., and Hardeland, R. (1991). Photoperiodism and effects of indoleamines in a unicellular alga. Science 253, 795-797.

Balzer, I., and Hardeland, R. (1996). Melatonin in algae and higher plants - Possible new roles as a phytohormone and antioxidant. Bot. Acta 109, 180-183. doi: 10.1111/j.1438-8677.1996.tb00560.x

Balzer, I., Poeggeler, B., and Hardeland, R. (1993). "Circadian rhythms of indoleamines in a dinoflagellate, Gonyaulax polyedra: persistence of melatonin rhythm in constant darkness and relationship to 5-methoxytryptamine," in Melatonin and the Pineal Gland - From Basic Science to Clinical Application, eds Y. Touitou, J. Arendt, and P. Pévet (Amsterdam: Excerpta Medica), 183-186.

Banerjee, S., and Margulis, L. (1973). Mitotic arrest by melatonin. Exp. Cell Res. 78, 314-318. doi: 10.1016/0014-4827(73)90074-8

Barberà, M., Mengual, B., Collantes-Alegre, J. M., Cortés, T., González, A., and Martínez-Torres, D. (2013). Identification, characterization and analysis of expression of genes encoding arylalkylamine $\mathrm{N}$-acetyltransferase in the pea aphid Acyrthosiphon pisum. Insect Mol. Biol. 22, 623-634. doi: 10.1111/imb.12050

Behrmann, G., Fuhrberg, B., Hardeland, R., Uría, H., and Poeggeler, B. (1997). Photooxidation of melatonin, 5-methoxytryptamine and 5methoxytryptophol: aspects of photoprotection by periodically fluctuating molecules? Biometeorology 14(Pt 2), 258-263.

Brown, P. N., Turi, C. E., Shipley, P. R., and Murch, S. J. (2012). Comparisons of large (Vaccinium macrocarpon Ait.) and small (Vaccinium oxycoccos L., Vaccinium vitis-idaea L.) cranberry in British Columbia by phytochemical determination, antioxidant potential, and metabolomic profiling with chemometric analysis. Planta Med. 78, 630-640. doi: 10.1055/s0031-1298239

Byeon, Y., and Back, K. (2014). Melatonin synthesis in rice seedlings in vivo is enhanced at high temperatures and under dark conditions due to increased serotonin $\mathrm{N}$-acetyltransferase and $\mathrm{N}$-acetylserotonin methyltransferase activities. J. Pineal Res. 56, 189-195. doi: 10.1111/jpi.12111

Byeon, Y., and Back, K. (2015). Molecular cloning of melatonin 2-hydroxylase responsible for 2-hydroxymelatonin production in rice (Oryza sativa). J. Pineal Res. 58, 343-351. doi: 10.1111/jpi.12220
Byeon, Y., Choi, G.-H., Lee, H. Y., and Back, K. (2015a). Melatonin biosynthesis requires expression of caffeic acid O-methyltransferase in rice. J. Exp. Bot. 66, 6917-6925. doi: 10.1093/jxb/erv396

Byeon, Y., Lee, H. J., Lee, H. Y., and Back, K. (2016). Cloning and functional characterization of the Arabidopsis $\mathrm{N}$-acetylserotonin O-methyltransferase responsible for melatonin synthesis. J. Pineal Res. 60, 65-73. doi: 10.1111/jpi.12289 [Epub ahead of print].

Byeon, Y., Lee, H. Y., Hwang, O. J., Lee, H. J., Lee, K., and Back, K. (2015b). Coordinated regulation of melatonin synthesis and degradation genes in rice leaves in response to cadmium treatment. J. Pineal Res. 58, 470-478. doi: 10.1111/jpi.12232

Byeon, Y., Lee, H. Y., Lee, K., and Back, K. (2014a). Caffeic acid $O$-methyltransferase is involved in the synthesis of melatonin by methylating N-acetylserotonin in Arabidopsis. J. Pineal Res. 57, 219-227. doi: $10.1111 /$ jpi.12160

Byeon, Y., Lee, H. Y., Lee, K., Park, S., and Back, K. (2014b). Cellular localization and kinetics of the rice melatonin biosynthetic enzymes SNAT and ASMT. J. Pineal Res. 56, 107-114. doi: 10.1111/jpi.12103

Byeon, Y., Lee, K., Park, Y.-I., Park, S., and Back, K. (2013). Molecular cloning and functional analysis of serotonin $\mathrm{N}$-acetyltransferase from the cyanobacterium Synechocystis sp. PCC 6803. J. Pineal Res. 55, 371-376. doi: 10.1111/jpi. 12080

Byeon, Y., Park, S., Lee, H. Y., Kim, Y.-S., and Back, K. (2014c). Elevated production of melatonin in transgenic rice seeds expressing rice tryptophan decarboxylase. J. Pineal Res. 56, 275-282. doi: 10.1111/jpi.12120

Byeon, Y., Tan, D.-X., Reiter, R. J., and Back, K. (2015c). Predominance of 2hydroxymelatonin over melatonin in plants. J. Pineal Res. 59, 448-454. doi: 10.1111/jpi.12274

Caniato, R., Filippini, R., Piovan, A., Ouricelli, L., Borsarinin, A., and Cappelletti, E. M. (2003). Melatonin in plants. Adv. Exp. Med. Biol. 527, 593-597. doi: 10.1007/978-1-4615-0135-0_68

Chan, Z., and Shi, H. (2015). Improved abiotic stress tolerance of bermudagrass by exogenous small molecules. Plant Signal. Behav. 10:e991577. doi: 10.4161/15592324.2014991577

Chen, Q., Qi, W. B., Reiter, R. J., Wie, W., and Wang, B. M. (2009). Exogenously applied melatonin stimulates root growth and raises endogenous indoleacetic acid in roots of etiolated seedlings of Brassica juncea. J. Plant Physiol. 166, 324-328. doi: 10.1016/j.jplph.2008.06.002

Conti, A., Tettamanti, C., Singaravel, M., Haldar, C., Pandi-Perumal, R. S., and Maestroni, G. J. M. (2002). "Melatonin: an ubiquitous and evolutionary hormone," in Treatise on Pineal Gland and Melatonin, eds C. Haldar, M. Singaravel, and S. K. Maitra (Enfield, NH: Science Publishers), 105-143.

de Almeida, E. A., Martinez, G. R., Klitzke, C. F., de Medeiros, M. H. G., and Di Mascio, P. (2003). Oxidation of melatonin by singlet molecular oxygen $(\mathrm{O} 2(1 \Delta \mathrm{g}))$ produces N1-acetyl-N2-formyl-5-methoxykynurenine. J. Pineal Res. 35, 131-137. doi: 10.1034/j.1600-079X.2003.00066.x

Dubbels, R., Reiter, R. J., Klenke, E., Goebel, A., Schnakenberg, E., Ehlers, C., et al. (1995). Melatonin in edible plants identified by radioimmunoassay and by high performance liquid-chromatography-mass spectrometry. J. Pineal Res. 18, 28-31. doi: 10.1111/j.1600-079X.1995.tb00136.x

Fuhrberg, B., Balzer, I., Hardeland, R., Werner, A., and Lüning, K. (1996). The vertebrate pineal hormone melatonin is produced by the brown alga Pterygophora californica and mimics dark effects on growth rate in the light. Planta (Berlin) 200, 125-131. doi: 10.1007/BF00196659

Guenther, A. L., Schmidt, S. I., Laatsch, H., Fotso, S., Ness, H., Ressmeyer, A.-R., et al. (2005). Reactions of the melatonin metabolite AMK (N1acetyl-5-methoxykynuramine) with reactive nitrogen species: formation of novel compounds, 3-acetamidomethyl-6-methoxycinnolinone and 3nitro-AMK. J. Pineal Res. 39, 251-260. doi: 10.1111/j.1600-079X.2005. 00242.x

Han, Q., Robinson, H., Ding, H., Christensen, D. M., and Li, J. (2012). Evolution of N-acetyltransferases: structural evidence from the yellow fever mosquito, Aedes aegypti. Proc. Natl. Acad. Sci. U.S.A. 109, 11669-11674. doi: 10.1073/pnas.1206828109

Hardeland, R. (1997). New actions of melatonin and their relevance to biometeorology. Int. J. Biometeorol. 41, 47-57. doi: 10.1007/s004840050053

Hardeland, R. (1999). Melatonin and 5-methoxytryptamine in non-metazoans. Reprod. Nutr. Dev. 39, 399-408. doi: 10.1051/rnd:19990311 
Hardeland, R. (2005). Antioxidative protection by melatonin - Multiplicity of mechanisms from radical detoxification to radical avoidance. Endocrine 27, 119-130. doi: 10.1385/ENDO:27:2:119

Hardeland, R. (2008). Melatonin, hormone of darkness and more - occurrence, control mechanisms, actions and bioactive metabolites. Cell Mol. Life Sci. 65, 2001-2018. doi: 10.1007/s00018-008-8001-x

Hardeland, R. (2010). Melatonin metabolism in the central nervous system. Curr. Neuropharmacol. 8, 168-181. doi: 10.2174/157015910792246244

Hardeland, R. (2015). Melatonin in plants and other phototrophs - advances and gaps concerning the diversity of functions. J. Exp. Bot. 66, 627-646. doi: 10.1093/jxb/eru386

Hardeland, R., Backhaus, C., and Fadavi, A. (2007a). Reactions of the NO redox forms $\mathrm{NO}^{+}, \mathrm{NO}$ and $\mathrm{HNO}$ (protonated NO-) with the melatonin metabolite N1-acetyl-5-methoxykynuramine. J. Pineal Res. 43, 382-388. doi: 10.1111/j.1600-079X.2007.00489.x

Hardeland, R., Balzer, I., Poeggeler, B., Fuhrberg, B., Uría, H., Behrmann, G., et al. (1995). On the primary functions of melatonin in evolution: mediation of photoperiodic signals in a unicell, photooxidation and scavenging of free radicals. J. Pineal Res. 18, 104-111. doi: 10.1111/j.1600-079X.1995.tb00147.x

Hardeland, R., Cardinali, D. P., Srinivasan, V., Spence, D. W., Brown, G. M., and Pandi-Perumal, S. R. (2011). Melatonin - A pleiotropic, orchestrating regulator molecule. Prog. Neurobiol. 93, 350-384. doi: 10.1016/j.pneurobio. 2010.12.004

Hardeland, R., and Fuhrberg, B. (1996). Ubiquitous melatonin - Presence and effects in unicells, plants and animals. Trends Comp. Biochem. Physiol. 2, 25-45.

Hardeland, R., Fuhrberg, B., Burkhardt, S., Poeggeler, B., and Lax, P. (1997). Aryl acylamidase and tryptophan hydroxylase, two key enzymes of 5methoxytryptamine formation in the dinoflagellate Gonyaulax polyedra, are regulated by a circadian oscillator, by melatonin and by temperature. Biometeorology 14(Pt 2), 278-285.

Hardeland, R., Pandi-Perumal, S. R., and Poeggeler, B. (2007b). Melatonin in plants - Focus on a vertebrate night hormone with cytoprotective properties. Funct. Plant Sci. Biotechnol. 1, 32-45.

Hardeland, R., and Poeggeler, B. (2003). Non-vertebrate melatonin. J. Pineal Res. 34, 233-241. doi: 10.1034/j.1600-079X.2003.00040.x

Hardeland, R., Poeggeler, B., Niebergall, R., and Zelosko, V. (2003). Oxidation of melatonin by carbonate radicals and chemiluminescence emitted during pyrrole ring cleavage. J. Pineal Res. 34, 17-25. doi: 10.1034/j.1600079X.2003.02941.x

Hardeland, R., Tan, D.-X., and Reiter, R. J. (2009). Kynuramines, metabolites of melatonin and other indoles: the resurrection of an almost forgotten class of biogenic amines. J. Pineal Res. 47, 109-126. doi: 10.1111/j.1600079X.2009.00701.x

Hasan, M. K., Ahammed, G. J., Yin, L., Shi, K., Xia, X., Zhou, Y., et al. (2015). Melatonin mitigates cadmium phytotoxicity through modulation of phytochelatins biosynthesis, vacuolar sequestration, and antioxidant potential in Solanum lycopersicum. Front. Plant Sci. 6:601. doi: 10.3389/fpls.2015.00601

Hattori, A., Migitaka, H., Iigo, M., Itoh, M., Yamamoto, K., Ohtani-Kaneko, R., et al. (1995). Identification of melatonin in plants and its effects on plasma melatonin levels and binding to melatonin receptors in vertebrates. Biochem. Mol. Biol. Int. 35, 627-634.

He, M., Wang, Y., Hua, W., Zhang, Y., and Wang, Z. (2012). De novo sequencing of Hypericum perforatum transcriptome to identify potential genes involved in the biosynthesis of active metabolites. PLOS ONE 7:e42081. doi: 10.1371/journal.pone.0042081

Hernández, I. G., Gomez, F. J., Cerutti, S., Arana, M. V., and Silva, M. F. (2015). Melatonin in Arabidopsis thaliana acts as plant growth regulator at low concentrations and preserves seed viability at high concentrations. Plant Physiol. Biochem. 94, 191-196. doi: 10.1016/j.plaphy.2015.06.011

Hiragaki, S., Suzuki, T., Mohamed, A. A., and Takeda, M. (2015). Structures and functions of insect arylalkylamine $\mathrm{N}$-acetyltransferase (iaaNAT), a key enzyme for physiological and behavioral switch in arthropods. Front. Physiol. 6:113. doi: 10.3389/fphys.2015.00113

Jackson, W. T. (1969). Regulation of mitosis. II. Interaction of isopropyl N-phenylcarbamate and melatonin. J. Cell Sci. 5, 745-755.

Jibran, R., Hunter, D. A., and Dijkwel, P. P. (2013). Hormonal regulation of leaf senescence through integration of developmental and stress signals. Plant Mol. Biol. 82, 547-561. doi: 10.1007/s11103-013-0043-2
Jones, M. P. A., Cao, J., O’Brien, R., Murch, S. J., and Saxena, P. K. (2007). The mode of action of thidiazuron: auxins, indoleamines, and ion channels in the regeneration of Echinacea purpurea L. Plant Cell Rep. 26, 1481-1490. doi: 10.1007/s00299-007-0357-0

Khan, M., Rozhon, W., and Poppenberger, B. (2014). The role of hormones in the aging of plants - a mini-review. Gerontology 60, 49-55. doi: 10.1159/ 000354334

Kolář, J., and Macháčková, I. (2005). Melatonin in higher plants: occurrence and possible functions. J. Pineal Res. 39, 333-341. doi: 10.1111/j.1600079X.2005.00276.x

Kolář, J., Macháčková, I., Eder, J., Prinsen, E., Van Dongen, W., Van Onckelen, H., et al. (1997). Melatonin: occurrence and daily rhythm in Chenopodium rubrum. Phytochemistry 44, 1407-1413. doi: 10.1016/S0031-9422(96)00568-7

Kolář, J., Macháčková, I., and Johnson, C. H. (1999). Effects of a melatonin analogue CGP 52608 in the photoperiodic flower induction in a short-day plant, Chenopodium rubrum. Biol. Rhythm Res. 30:243.

Kostopoulou, Z., Therios, I., Roumeliotis, E., Kanellis, A. K., and Molassiotis, A. (2015). Melatonin combined with ascorbic acid provides salt adaptation in Citrus aurantium L. seedlings. Plant Physiol. Biochem. 86, 155-165. doi: 10.1016/j.plaphy.2014.11.021

Koyama, F. C., Carvalho, T. L. G., Alves, E., da Silva, H. B., de Azevedo, M. F., Hemerly, A. S., et al. (2013). The structurally related auxin and melatonin tryptophan-derivatives and their roles in Arabidopsis thaliana and in the human malaria parasite Plasmodium falciparum. J. Eukaryot. Microbiol. 60, 646-651. doi: $10.1111 /$ jeu. 12080

Lee, H. Y., Byeon, Y., and Back, K. (2014a). Melatonin as a signal molecule triggering defense responses against pathogen attack in Arabidopsis and tobacco. J. Pineal Res. 57, 262-268. doi: 10.1111/jpi.12165

Lee, H. Y., Byeon, Y., Lee, K., Lee, H. J., and Back, K. (2014b). Cloning of Arabidopsis serotonin $\mathrm{N}$-acetyltransferase and its role with caffeic acid O-methyltransferase in the biosynthesis of melatonin in vitro despite their different subcellular localizations. J. Pineal Res. 57, 418-426. doi: 10.1111/jpi.12181

Lee, H. Y., Byeon, Y., Tan, D.-X., Reiter, R. J., and Back, K. (2015). Arabidopsis serotonin $\mathrm{N}$-acetyltransferase knockout mutant plants exhibit decreased melatonin and salicylic acid levels resulting in susceptibility to an avirulent pathogen. J. Pineal Res. 58, 291-299. doi: 10.1111/jpi.12214

Lei, Q., Wang, L., Tan, D.-X., Zhao, Y., Zheng, X.-D., Chen, H., et al. (2013). Identification of genes for melatonin synthetic enzymes in 'Red Fuji' apple (Malus domestica Borkh.cv.Red) and their expression and melatonin production during fruit development. J. Pineal Res. 55, 443-451. doi: 10.1111/jpi.12096

Li, C., Tan, D.-X., Liang, D., Chang, C., Jia, D., and Ma, F. (2015). Melatonin mediates the regulation of ABA metabolism, free-radical scavenging, and stomatal behaviour in two Malus species under drought stress. J. Exp. Bot. 66, 669-680. doi: 10.1093/jxb/eru476

Liang, C., Zheng, G., Li, W., Wang, Y., Hu, B., Qian, Y., et al. (2015). Melatonin delays leaf senescence and enhances salt stress tolerance in rice. J. Pineal Res. 59, 91-101. doi: 10.1111/jpi.12243

Liu, T., and Borjigin, J. (2005). N-acetyltransferase is not the rate-limiting enzyme of melatonin synthesis at night. J. Pineal Res. 39, 91-96. doi: 10.1111/j.1600079X.2005.00223.x

Manchester, L. C., Tan, D.-X., Reiter, R. J., Park, W., Monis, K., and Qi, W. (2000). High levels of melatonin in the seeds of edible plants. Possible function in germ tissue protection. Life Sci. 67, 3023-3029. doi: 10.1016/S0024-3205(00)00896-1

Mukherjee, S., David, A., Yadav, S., Baluška, F., and Bhatla, S. C. (2014). Salt stressinduced growth inhibition coincides with differential distribution of serotonin and melatonin in subflower seedling roots and cotyledons. Physiol. Plant. 152 714-728. doi: 10.1111/ppl.12218

Murch, S. J., Alan, A. R., Cao, J., and Saxena, P. K. (2009). Melatonin and serotonin in flowers and fruits of Datura metel L. J. Pineal Res. 47, 277-283. doi: 10.1111/j.1600-079X.2009.00711.x

Murch, S. J., Hall, B. A., Le, C. H., and Saxena, P. K. (2010). Changes in the levels of indoleamine phytochemicals during véraison and ripening of wine grapes. J. Pineal Res. 49, 95-100. doi: 10.1111/j.1600-079X.2010.00774.x

Murch, S. J., and Saxena, P. K. (2002). Mammalian neurohormones: potential significance in reproductive physiology of St. John's wort (Hypericum perforatum L.)? Naturwissenschaften $89,555-560$. 
Okazaki, M., Higuchi, K., Aouini, A., and Ezura, H. (2010). Lowering intercellular melatonin levels by transgenic analysis of indoleamine 2,3-dioxygenase from rice in tomato plants. J. Pineal Res. 49, 239-247. doi: 10.1111/j.1600079X.2010.00788.x

Oladi, E., Mohamadi, M., Shamspur, T., and Mostafavi, A. (2014). Spectrofluorimetric determination of melatonin in kernels of four different Pistacia varieties after ultrasound-assisted solid-liquid extraction. Spectrochim. Acta A Mol. Biomol. Spectrosc. 132, 326-329. doi: 10.1016/j.saa.2014.05.010

Paquette, S. M., Bak, S., and Feyereisen, R. (2000). Intron-exon organization and phylogeny in a large superfamily, the paralogous cytochrome P450 genes of Arabidopsis thaliana. DNA Cell Biol. 19, 307-317. doi: 10.1089/10445490050021221

Paredes, S. D., Korkmaz, A., Manchester, L. C., Tan, D.-X., and Reiter, R. J. (2009). Phytomelatonin: a review. J. Exp. Bot. 60, 57-69. doi: 10.1093/jxb/ern284

Park, M., Kang, K., Park, S., and Back, K. (2008). Conversion of 5hydroxytryptophan into serotonin by tryptophan decarboxylase in plants, Escherichia coli, and yeast. Biosci. Biotechnol. Biochem. 72, 2456-2458. doi: $10.1271 /$ bbb. 80220

Park, S., Byeon, Y., and Back, K. (2013a). Transcriptional suppression of tryptamine 5-hydroxylase, a terminal serotonin biosynthetic gene, induces melatonin biosynthesis in rice (Oryza sativa L.). J. Pineal Res. 55, 131-137. doi: 10.1111/jpi.12053

Park, S., Byeon, Y., and Back, K. (2013b). Functional analyses of three ASMT gene family members in rice plants. J. Pineal Res. 55, 409-415. doi: 10.1111/jpi.12088

Park, S., Byeon, Y., Kim, Y.-S., and Back, K. (2013c). Kinetic analysis of purified recombinant rice $\mathrm{N}$-acetylserotonin methyltransferase and peak melatonin production in etiolated rice shoots. J. Pineal Res. 54, 139-144. doi: 10.1111/j.1600-079X.2012.01019.x

Park, S., Byeon, Y., Lee, H. Y., Kim, Y. S., Ahn, T., and Back, K. (2014). Cloning and characterization of a serotonin $\mathrm{N}$-acetyltransferase from a gymnosperm, loblolly pine (Pinus taeda). J. Pineal Res. 57, 348-355. doi: 10.1111/jpi.12174

Park, S., Le, T.-N. N., Byeon, Y., Kim, Y. S., and Back, K. (2013d). Transient induction of melatonin biosynthesis in rice (Oryza sativa L.) during reproductive stage. J. Pineal Res. 55, 40-45. doi: 10.1111/jpi.12021

Park, S., Lee, K., Kim, Y. S., and Back, K. (2012). Tryptamine 5-hydroxylasedeficient Sekiguchi rice induces synthesis of 5-hydroxytryptophan and $\mathrm{N}$-acetyltryptamine but decreases melatonin biosynthesis during senescence of detached rice leaves. J. Pineal Res. 52, 211-216. doi: 10.1111/j.1600079X.2011.00930.x

Poeggeler, B., Balzer, I., Fischer, J., Behrmann, G., and Hardeland, R. (1989). A role of melatonin in dinoflagellates? Acta Endocrinol.(Cop.) 120(Suppl. 1), 97.

Poeggeler, B., Balzer, I., Hardeland, R., and Lerchl, A. (1991). Pineal hormone melatonin oscillates also in the dinoflagellate Gonyaulax polyedra. Naturwissenschaften 78, 268-269. doi: 10.1007/BF01134354

Qian, Y., Tan, D.-X., Reiter, R. J., and Shi, H. (2015). Comparative metabolomic analysis highlights the involvement of sugars and glycerol in melatoninmediated innate immunity against bacterial pathogen in Arabidopsis. Sci. Rep. 5:15815. doi: $10.1038 /$ srep 15815

Ramakrishna, A., Giridhar, P., Udaya Sankar, K., and Ravishankar, G. A. (2012). Melatonin and serotonin profiles in beans of Coffea species. J. Pineal Res. 52, 470-476. doi: 10.1111/j.1600-079X.2011.00964.x

Ressmeyer, A.-R., Mayo, J. C., Zelosko, V., Sáinz, R. M., Tan, D.-X., Poeggeler, B., et al. (2003). Antioxidant properties of the melatonin metabolite N1-acetyl5-methoxykynuramine (AMK): scavenging of free radicals and prevention of protein destruction. Redox Rep. 8, 205-213. doi: 10.1179/135100003225002709

Rosen, J., Than, N. N., Koch, D., Poeggeler, B., Laatsch, H., and Hardeland, R. (2006). Interactions of melatonin and its metabolites with the ABTS cation radical: extension of the radical scavenger cascade and formation of a novel class of oxidation products, $\mathrm{C}_{2}$-substituted 3-indolinones. J. Pineal Res. 41, 374-381. doi: 10.1111/j.1600-079X.2006.00379.x

Schaefer, M., and Hardeland, R. (2009). The melatonin metabolite N1-acetyl-5methoxykynuramine is a potent singlet oxygen scavenger. J. Pineal Res. 46, 49-52. doi: 10.1111/j.1600-079X.2008.00614.x

Shi, H., and Chan, Z. (2014). The cystein2/histidine2-type transcription factor ZINC FINGER OF ARABIDOPSIS THALIANA 6-activated C-REPEATBINDING FACTOR pathway is essential for melatonin mediated freezing stress resistance in Arabidopsis. J. Pineal Res. 57, 185-191. doi: 10.1111/jpi. 12155
Shi, H., Chen, Y., Tan, D.-X., Reiter, R. J., Chan, Z., and He, C. (2015a). Melatonin induces nitric oxide and the potential mechanisms relate to innate immunity against bacterial pathogen infection in Arabidopsis. J. Pineal Res. 59, 102-108. doi: $10.1111 /$ jpi.12244

Shi, H., Jiang, C., Ye, T., Tan, D.-X., Reiter, R. J., Zhang, H., et al. (2015b). Comparative physiological, metabolomic, and transcriptomic analyses reveal mechanisms of improved abiotic stress resistance in bermudagrass [Cynodon dactylon (L.). Pers.] by exogenous melatonin. J. Exp. Bot. 66, 681-694. doi: 10.1093/jxb/eru373

Shi, H., Qian, Y., Tan, D.-X., Reiter, R. J., and He, C. (2015c). Melatonin induces the transcripts of CBF/DREB1s and their involvement in both abiotic and biotic stresses in Arabidopsis. J. Pineal Res. 59, 334-342. doi: 10.1111/jpi. 12262

Shi, H., Reiter, R. J., Tan, D., and Chan, Z. (2015d). INDOLE-3-ACETIC ACID INDUCIBLE 17 positively modulates natural leaf senescence through melatonin-mediated pathway in Arabidopsis. J. Pineal Res. 58, 26-33. doi: 10.1111/jpi.12188

Shi, H., Tan, D.-X., Reiter, R. J., Ye, T., Yang, F., and Chan, Z. (2015e). Melatonin induces class A1 heat-shock factors (HSFA1s) and their possible involvement of thermotolerance in Arabidopsis. J. Pineal Res. 58, 335-342. doi: 10.1111/jpi.12219

Shi, H., Wang, X., Tan, D.-X., Reiter, R. J., and Chan, Z. (2015f). Comparative physiological and proteomic analyses reveal the actions of melatonin in the reduction of oxidative stress in Bermuda grass (Cynodon dactylon (L.) Pers.). J. Pineal Res. 59, 120-131. doi: 10.1111/jpi.12246

Slominski, A., Fischer, T. W., Zmijewski, M. A., Wortsman, J., Semak, I., Zbytek, B., et al. (2005). On the role of melatonin in skin physiology and pathology. Endocrine 27, 137-148. doi: 10.1385/ENDO:27:2:137

Slominski, A. T., Kim, T. K., Takeda, Y., Janjetovic, Z., Brozyna, A. A., Skobowiat, C., et al. (2014). ROR $\alpha$ and ROR $\gamma$ are expressed in human skin and serve as receptors for endogenously produced noncalcemic 20-hydroxy- and 20,23-dihydroxyvitamin D. FASEB J. 28, 2775-2789. doi: 10.1096/fj.13-242040

Sprenger, J., Hardeland, R., Fuhrberg, B., and Han, S.-Z. (1999). Melatonin and other 5-methoxylated indoles in yeast: presence in high concentrations and dependence on tryptophan availability. Cytologia (Tokyo) 64, 209-213. doi: 10.1508/cytologia.64.209

Tan, D.-X., Hardeland, R., Manchester, L. C., Galano, A., and Reiter, R. J. (2014a). Cyclic-3-hydroxymelatonin (C3HOM), a potent antioxidant, scavenges free radicals and suppresses oxidative reactions. Curr. Med. Chem. 21, 1557-1565. doi: 10.2174/0929867321666131129113146

Tan, D.-X., Hardeland, R., Manchester, L. C., Korkmaz, A., Ma, S., RosalesCorral, S., et al. (2012). Functional roles of melatonin in plants and perspectives in nutritional and agricultural science. J. Exp. Bot. 63, 577-597. doi: $10.1093 /$ jxb/err256

Tan, D.-X., Hardeland, R., Manchester, L. C., Poeggeler, B., Lopez-Burillo, S., Mayo, J. C., et al. (2003). Mechanistic and comparative studies of melatonin and classic antioxidants in terms of their interactions with the ABTS cation radical. J. Pineal Res. 34, 249-259. doi: 10.1034/j.1600-079X.2003.00037.x

Tan, D.-X., Manchester, L. C., Di Mascio, P., Martinez, G. R., Prado, F. M., and Reiter, R. J. (2007). Novel rhythms of N1-acetyl-N2-formyl5-methoxykynuramine and its precursor melatonin in water hyacinth: importance for phytoremediation. FASEB J. 21, 1724-1729. doi: 10.1096/fj.06$7745 \mathrm{com}$

Tan, D.-X., Manchester, L. C., Liu, X., Rosales-Corral, S. A., Acuna-Castroviejo, D., and Reiter, R. J. (2013). Mitochondria and chloroplasts as the original sites of melatonin synthesis: a hypothesis related to melatonin's primary function and evolution in eukaryotes. J. Pineal Res. 54, 127-138. doi: 10.1111/jpi. 12026

Tan, D.-X., Manchester, L. C., Reiter, R. J., Plummer, B. F., Hardies, L. J., Weintraub, S. T., et al. (1998). A novel melatonin metabolite, cyclic 3-hydroxymelatonin: a biomarker of in vivo hydroxyl radical generation. Biochem. Biophys. Res. Commun. 253, 614-620. doi: 10.1006/bbrc.1998.9826

Tan, D.-X., Reiter, R. J., Manchester, L. C., Yan, M. T., El-Sawi, M., Sainz, R. M., et al. (2002). Chemical and physical properties and potential mechanisms: melatonin as a broad spectrum antioxidant and free radical scavenger. Curr. Top. Med. Chem. 2, 181-197. doi: 10.2174/1568026023394443

Tan, D.-X., Zheng, X., Kong, J., Manchester, L. C., Hardeland, R., Kim, S. J., et al. (2014b). Fundamental issues related to the origin of melatonin and melatonin 
isomers during evolution: relation to their biological functions. Int. J. Mol. Sci. 15, 15858-15890. doi: 10.3390/ijms150915858

Tiryaki, I., and Keles, H. (2012). Reversal of inhibitory effect of light and high temperature on germination of Phacelia tanacetifolia seeds by melatonin. J. Pineal Res. 52, 332-339. doi: 10.1111/j.1600-079X.2011.00947.x

Torrens-Spence, M. P., Lazear, M., von Guggenberg, M., Ding, H., Harich, K., and Li, J. (2014). Investigation of a substrate-specifying residue within Papaver somniferum and Catharanthus roseus aromatic amino acid decarboxylases. Phytochemistry 106, 37-43. doi: 10.1016/j.phytochem.2014.07.007

Torrens-Spence, M. P., Liu, P., Ding, H., Harich, K., Gillaspy, G., and Li, J. (2013). Biochemical evaluation of the decarboxylation and decarboxylationdeamination activities of plant aromatic amino acid decarboxylases. J. Biol. Chem. 288, 2376-2387. doi: 10.1074/jbc.M112.401752

Wang, L., Zhao, Y., Reiter, R. J., He, C., Liu, G., Lei, Q., et al. (2014b). Changes in melatonin levels in transgenic 'Micro-Tom' tomato overexpressing ovine AANAT and ovine HIOMT genes. J. Pineal Res. 56, 134-142. doi: 10.1111/jpi.12105

Wang, P., Sun, X., Chang, C., Feng, F., Liang, D., Cheng, L., et al. (2013). Delay in leaf senescence of Malus hupehensis by long-term melatonin application is associated with its regulation of metabolic status. J. Pineal Res. 55, 424-434. doi: 10.1111/jpi.12091

Wang, P., Sun, X., Wang, N., Tan, D.-X., and Reiter, R. J. (2015). Melatonin enhances the occurrence of autophagy induced by oxidative stress in Arabidopsis seedlings. J. Pineal Res. 58, 479-489. doi: 10.1111/jpi.12233

Wang, P., Sun, X., Xie, Y., Li, M., Chen, W., Zhang, S., et al. (2014a). Melatonin regulates proteomic changes during leaf senescence in Malus hupehensis. J. Pineal Res. 57, 291-307. doi: 10.1111/jpi.12169

Wang, P., Yin, L., Liang, D., Li, C., Ma, F., and Yue, Z. (2012). Delayed senescence of apple leaves by exogenous melatonin treatment: toward regulating the ascorbate-glutathione cycle. J. Pineal Res. 53, 11-20. doi: 10.1111/j.1600079X.2011.00966.x

Weeda, S., Zhang, N., Zhao, X., Ndip, G., Guo, Y., Buck, G. A., et al. (2014). Arabidopsis transcriptome analysis reveals key roles of melatonin in plant defense systems. PLOS ONE 9:e93462. doi: 10.1371/journal.pone. 0093462
Wei, W., Li, Q.-T., Chu, Y.-N., Reiter, R. J., Yu, X.-M., Zhu, D.-H., et al. (2015). Melatonin enhances plant growth and abiotic stress tolerance in soybean plants. J. Exp. Bot. 66, 695-707. doi: 10.1093/jxb/eru392

Zhang, H. J., Zhang, N., Yang, R. C., Wang, L., Sun, Q. Q., Li, D. B., et al. (2014). Melatonin promotes seed germination under high salinity by regulating antioxidant systems, ABA and GA4 interaction in cucumber (Cucumis sativus L.). J. Pineal Res. 57, 269-279. doi: 10.1111/jpi.12167

Zhang, N., Sun, Q., Zhang, H., Cao, Y., Weeda, S., Ren, S., et al. (2015). Roles of melatonin in abiotic stress resistance. J. Exp. Bot. 66, 647-656. doi: $10.1093 / \mathrm{jxb} / \mathrm{eru} 336$

Zhao, H., Su, T., Huo, L., Wei, H., Jiang, Y., Xu, L., et al. (2015a). Unveiling the mechanism of melatonin impacts on maize seedling growth: sugar metabolism as a case. J. Pineal Res. 59, 255-266. doi: 10.1111/jpi.12258

Zhao, H., Xu, L., Su, T., Jiang, Y., Hu, L., and Ma, F. (2015b). Melatonin regulates carbohydrate metabolism and defenses against Pseudomonas syringae pv. tomato DC3000 infection in Arabidopsis thaliana. J. Pineal Res. 59, 109-119. doi: 10.1111/jpi.12245

Zhong, L., Wang, K., Tan, J., Li, W., and Li, S. (2002). Putative cytochrome P450 genes in rice genome (Oryza sativa L. ssp. indica) and their EST evidence. Sci. China C Life Sci. 45, 512-517. doi: 10.1360/02yc9056

Zuo, B., Zheng, X., He, P., Wang, L., Lei, Q., Feng, C., et al. (2014). Overexpression of MzASMT improves melatonin production and enhances drought tolerance in transgenic Arabidopsis thaliana plants. J. Pineal Res. 57, 408-417. doi: 10.1111/jpi.12180

Conflict of Interest Statement: The author declares that the research was conducted in the absence of any commercial or financial relationships that could be construed as a potential conflict of interest.

Copyright $\odot 2016$ Hardeland. This is an open-access article distributed under the terms of the Creative Commons Attribution License (CC BY). The use, distribution or reproduction in other forums is permitted, provided the original author(s) or licensor are credited and that the original publication in this journal is cited, in accordance with accepted academic practice. No use, distribution or reproduction is permitted which does not comply with these terms. 